\title{
Tsunami source of the 2011 off the Pacific coast of Tohoku Earthquake
}

\author{
Yushiro Fujii ${ }^{1}$, Kenji Satake ${ }^{2}$, Shin'ichi Sakai ${ }^{2}$, Masanao Shinohara ${ }^{2}$, and Toshihiko Kanazawa ${ }^{2}$ \\ ${ }^{1}$ International Institute of Seismology and Earthquake Engineering (IISEE), Building Research Institute (BRI), \\ 1-3 Tachihara, Tsukuba, Ibaraki 305-0802, Japan \\ ${ }^{2}$ Earthquake Research Institute (ERI), University of Tokyo, 1-1-1 Yayoi, Bunkyo-ku, Tokyo 113-0032, Japan
}

(Received April 9, 2011; Revised June 6, 2011; Accepted June 7, 2011; Online published September 27, 2011)

\begin{abstract}
Tsunami waveform inversion for the 11 March, 2011, off the Pacific coast of Tohoku Earthquake (M 9.0) indicates that the source of the largest tsunami was located near the axis of the Japan trench. Ocean-bottom pressure, and GPS wave, gauges recorded two-step tsunami waveforms: a gradual increase of sea level $(\sim 2 \mathrm{~m})$ followed by an impulsive tsunami wave ( 3 to $5 \mathrm{~m}$ ). The slip distribution estimated from 33 coastal tide gauges, offshore GPS wave gauges and bottom-pressure gauges show that the large slip, more than $40 \mathrm{~m}$, was located along the trench axis. This offshore slip, similar but much larger than the 1896 Sanriku "tsunami earthquake," is responsible for the recorded large impulsive peak. Large slip on the plate interface at southern Sanriku-oki $(\sim 30 \mathrm{~m})$ and Miyagi-oki $(\sim 17 \mathrm{~m})$ around the epicenter, a similar location with larger slip than the previously proposed fault model of the 869 Jogan earthquake, is responsible for the initial water-level rise and, presumably, the large tsunami inundation in Sendai plain. The interplate slip is $\sim 10 \mathrm{~m}$ in Fukushima-oki, and less than $3 \mathrm{~m}$ in the Ibaraki-oki region. The total seismic moment is estimated as $3.8 \times 10^{22} \mathrm{~N} \mathrm{~m}\left(M_{\mathrm{w}}=9.0\right)$.
\end{abstract}

Key words: 2011 Tohoku Earthquake, slip distribution, tsunami waveform inversion, ocean-bottom pressure gauge, GPS wave gauge.

\section{Introduction}

A giant earthquake off the Pacific coast of Tohoku, Japan $\left(38.1035^{\circ} \mathrm{N}, 142.861^{\circ} \mathrm{E}, M 9.0\right.$ at $14: 46: 18 \mathrm{JST}$ according to Japan Meteorological Agency) on March 11, 2011, generated a huge tsunami and caused 15,729 fatalities and 4,539 missing in the Hokkaido, Tohoku and Kanto regions (The National Police Agency, as of 24 Aug. 2011). The USGS W-phase moment tensor solution shows a shallow dipping thrust mechanism with a strike parallel to the Japan trench, indicating an interplate earthquake associated with the subduction of the Pacific plate (Fig. 1). Continuous GPS data revealed coastal subsidence as great as one meter along the coast of the Tohoku area (Geospatial Information Authority of Japan (GSI), 2011).

The Pacific coasts of Tohoku have suffered from large tsunamis in the past. The 1896 Sanriku earthquake caused large (up to $38 \mathrm{~m}$ of run-up height) tsunamis on the Sanriku coast with 22,000 casualties, although the seismic shaking was not very strong. The source of the tsunami of this "tsunami earthquake" (Kanamori, 1972) was located near the trench axis (Tanioka and Satake, 1996b). The 1933 Sanriku earthquake, a large normal-fault earthquake (Kanamori, 1971) also caused a large (up to $29 \mathrm{~m}$ ) tsunami with about 3,000 casualties. The tsunami heights from these Sanriku earthquakes were less than a few meters in the Sendai plain. However, the 869 Jogan earthquake produced a large tsunami inundation up to a few kilometers (Minoura

Copyright (c) The Society of Geomagnetism and Earth, Planetary and Space Sciences (SGEPSS); The Seismological Society of Japan; The Volcanological Society of Japan; The Geodetic Society of Japan; The Japanese Society for Planetary Sciences; TERRAPUB.

doi:10.5047/eps.2011.06.010 and Nakaya, 1991), which was modeled by an interplate earthquake (Satake et al., 2008).

On the basis of large historical earthquakes, The Earthquake Research Committee (ERC) (2009) made long-term forecasts in northern, central, and southern Sanriku-oki, Miyagi-oki, Fukushima-oki and Ibaraki-oki regions, as well as tsunami earthquakes near the trench axis. The estimated earthquake size was $M \sim 7.7$ for southern Sanriku-oki, $M \sim 7.5$ for Miyagi-oki, $M \sim 7.4$ for Fukushima-oki, $M \sim 6.7-7.2$ for Ibaraki-oki, and $M \sim 8.2$ for offshore tsunami earthquakes. The ERC also considered a multiple segment rupture of the Miyagi-oki and southern Sanrikuoki regions with an estimated size of $M \sim 8.0$.

In this paper, we estimate the tsunami source of the 2011 Tohoku Earthquake by inverting tsunami waveforms recorded at tide and wave gauges, GPS wave gauges and ocean-bottom tsunami sensors.

\section{Tsunami Data}

Because of the severity and wide extent of the tsunami damage, tsunami field surveys are still ongoing. Preliminary surveys reported tsunami run-up heights exceeding $30 \mathrm{~m}$ (The 2011 Tohoku Earthquake Tsunami Joint Survey Group, 2011).

The 2011 tsunami was also recorded instrumentally at various gauges. Many coastal tide gauges on the Pacific coast stopped recording after the first tsunami with $>9 \mathrm{~m}$ amplitude, because of power failure or because the stations were washed away by the tsunami. Three offshore gauges, one GPS wave gauge (Iwate $\mathrm{S}$ at $\sim 200 \mathrm{~m}$ water depth) and two cabled pressure-gauges (TM- 2 at $\sim 1,000 \mathrm{~m}$ and TM- 1 at 1,600 $\mathrm{m}$ depth), recorded the two-stage tsunamis (Fig. 2). 


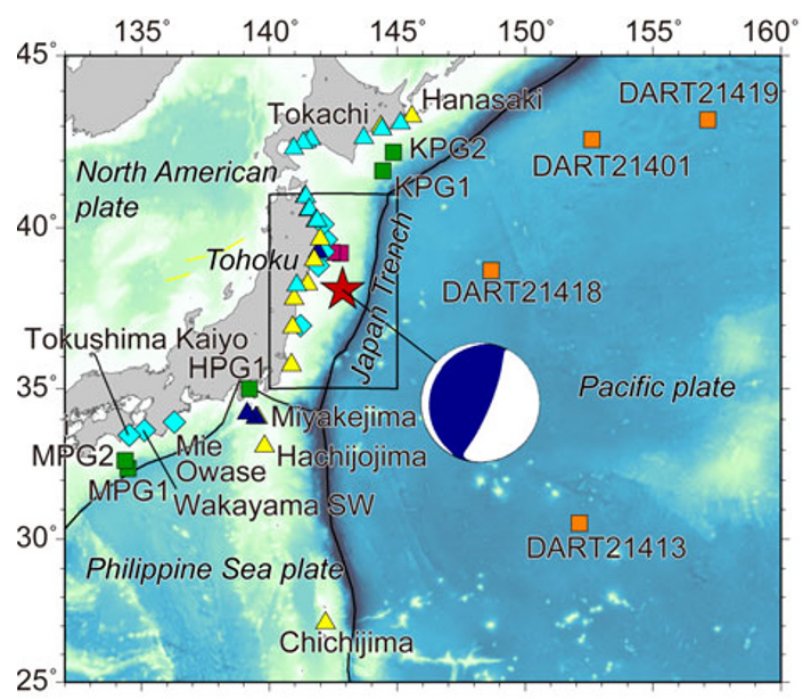

Fig. 1. Epicenter of the 2011 Tohoku Earthquake (red star), W-phase MT solution by USGS, and stations that recorded the tsunami. Triangles, diamonds and squares indicate the locations of coastal (tide or wave) gauges, offshore GPS wave gauges and ocean-bottom tsunami sensors or DART (Deep-ocean Assessment and Reporting of Tsunamis) systems, respectively. Colors indicate operating agencies (yellow: Japan Meteorological Agency (JMA), blue: Japan Coast Guard (JCG), green: Japan Agency for Marine-Earth Science and Technology (JAMSTEC), orange: National Oceanic \& Atmospheric Administration (NOAA), light blue: Japan's Nationwide Ocean Wave information network for Ports and HArbourS (NOWPHAS), and purple: University of Tokyo). The thin rectangle indicates the region shown in Fig. 3.

The water level gradually rose up to $2 \mathrm{~m}$ during the first 10 minutes, then an impulsive tsunami wave with 3-5 m amplitude having a shorter period $(\sim 8 \mathrm{~min})$ was recorded. At southern GPS (Fukushima) and coastal (Onahama) gauges, two similar pulses were recorded, although their periods were more similar to each other.

We use tsunami waveforms recorded at coastal tide and wave gauges, and offshore GPS wave gauges, deep-ocean bottom-pressure gauges (Fig. 1). While most of the coastal tide gauge stations went off-scale and did not record the tsunami peak, the arrival time and the initial slope recorded provide information on the tsunami source, hence we include them in the inversion. In order to retrieve a tsunami signal, we first approximate a tidal component by fitting a polynomial function, and then remove it from the original record.

\section{Waveform Inversion}

We divide the tsunami source into 40 subfaults $(50 \mathrm{~km}$ $\times 50 \mathrm{~km}$ ) to cover the aftershock area (Fig. 3 and Table 1). Strike $193^{\circ}$, dip $14^{\circ}$, slip angle $81^{\circ}$ are from the USGS's W-phase moment tensor solution. Static deformation of the seafloor is calculated for a rectangular fault model (Okada, 1985). We also consider the effects of coseismic horizontal displacement in regions of steep bathymetric slopes (Tanioka and Satake, 1996a). Tsunami waveforms are calculated assuming a constant rise time (or slip duration) of $30 \mathrm{~s}$ on each subfault, considering that the duration of the first pulse of source time function was $\sim 1$ min (e.g., USGS). We assume an instantaneous rupture. The slip distribution estimated from tsunami waveforms, however, is not sensi-
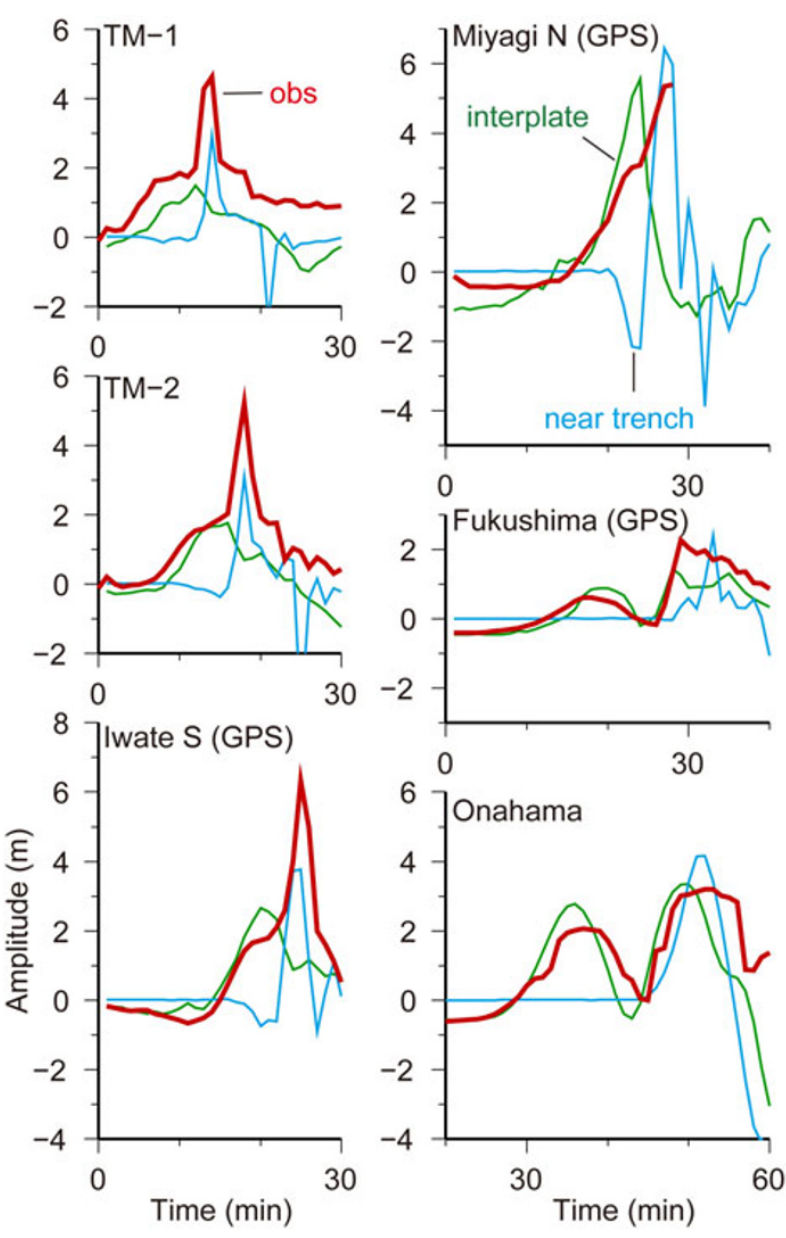

Fig. 2. The observed tsunami waveforms (red curves) at offshore bottom-pressure gauges (TM-1, TM-2), GPS wave gauges, and a coastal tide gauge. The original data were resampled at $1 \mathrm{~min}$ intervals. Blue and green curves are computed tsunami waveforms from the large slip near the trench (blue) and deeper interplate slip (green) as shown in Fig. 3(b).

tive to the choice of rise time or rupture velocity (Fujii and Satake, 2007).

To calculate tsunami propagation from each subfault to gauge stations, the linear shallow-water, or longwave, equations are numerically solved by using a finitedifference method (Fujii and Satake, 2007). Whilst the nonlinearity becomes important around coastal tide gauge stations, we have confirmed, by comparing the nonlinear and linear computations, that they produce similar arrival times and initial slopes, while the peak amplitudes (not observed) are different. We use two sets of bathymetric data for calculating tsunami waveforms or Green's functions. For the DART stations in the Pacific ocean, a $2^{\prime}$-interval grid for $125^{\circ}-175^{\circ} \mathrm{E}$ and $15^{\circ}-55^{\circ} \mathrm{N}$ is resampled from GEBCO_08 $30^{\prime \prime}$-grid data. For stations around Japan, a 30"-interval grid of JTOPO30, provided by the Marine Information Research Center, is used for $128^{\circ}-150^{\circ} \mathrm{E}$ and $25^{\circ}-45^{\circ} \mathrm{N}$. Time steps of $3 \mathrm{~s}$ and $1 \mathrm{~s}$ are used to satisfy the stability condition for the finite-difference method in the far-field and near-field computations, respectively.

For the inversion, we use a non-negative least-square method (Lawson and Hanson, 1974) and a delete-half jackknife method (Tichelaar and Ruff, 1989) to estimate slips 

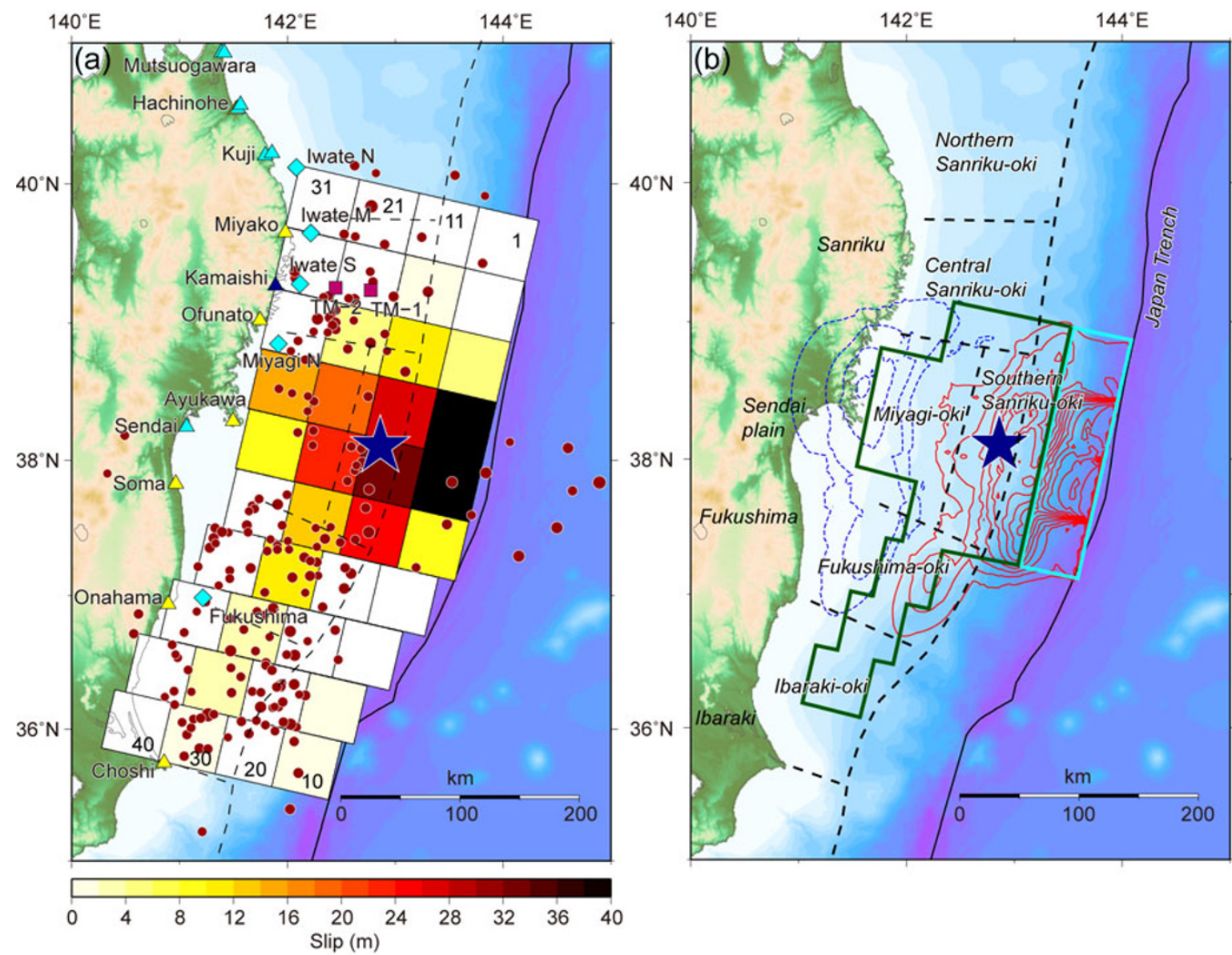

Fig. 3. (a) Slip distributions estimated by tsunami waveform inversion. The color bars are shown below. The subfault numbers are shown in the northernmost and southernmost subfaults. The star shows the mainshock epicenter. Circles indicate aftershocks within one day after the mainshock (JMA data). Dashed lines indicate regions where the probabilities and size of future subduction-zone earthquakes were estimated by the Earthquake Research Committee (2009). Coastal and offshore stations (the same symbol as Fig. 1) are also shown. (b) Seafloor deformation computed from the estimated slip distribution. The red solid contours indicate uplift with a contour interval of $1.0 \mathrm{~m}$, whereas the blue dashed contours indicate subsidence, with a contour interval of $0.5 \mathrm{~m}$. The light blue and dark green frames show the subfaults with $>2 \mathrm{~m}$ slips. The synthetic tsunami waveforms are computed from these two regions (near the trench axis and interplate slip) and shown in Fig. 2.

and errors, respectively. The observed tsunami waveforms were resampled at $1 \mathrm{~min}$ intervals, hence synthetic waveforms are also computed at 1 min intervals. The total number of data points used for the inversion is 2818 . Considering the different amplitude and signal durations of tsunami waveforms recorded on DART gauges, GPS gauges, and coastal tide gauge data, we use variable weights so that the relative powers become similar. We weight nearby GPS gauge and bottom-pressure data 10, 20, or 30 times, and near-source tide gauge data 2 times or 10 times, because the duration of these data are shorter than the far-field stations. We also weight the DART data ten times, because the amplitudes are much smaller.

\section{The Slip Distribution}

The inversion results are shown in Fig. 3(a) and Table 1. The result shows a tsunami source length (with $>2 \mathrm{~m}$ slip) of about $350 \mathrm{~km}$, extending from over southern Sanriku-oki, Miyagi-oki, Fukushima-oki as well as near the trench axis. The largest slips of more than $40 \mathrm{~m}$ are estimated along the Japan trench axis off southern Sanriku-oki (subfaults 4 and 5). Around the epicenter, in the southern Sanriku region (subfaults 14 and 15), the estimated slip is $28-34 \mathrm{~m}$. On the deeper subfault in the Miyagi-oki region (subfaults 24, 25, 34 and 35), the slip is 9-23 m. To the north of the epicenter, 5-11 m slip is estimated in a part of central Sanriku region (subfault 13 and 23). To the south, the slip is $\sim 10 \mathrm{~m}$ in the Fukushima-oki region (subfaults 27 and 28), and $<3 \mathrm{~m}$ in the Ibaraki-oki region (subfaults 29 and 30). The total seismic moment is calculated from these slip distributions as $3.8 \times 10^{21} \mathrm{~N} \mathrm{~m}\left(M_{\mathrm{w}}=9.0\right)$ by assuming a rigidity of $5.0 \times 10^{10} \mathrm{~N} / \mathrm{m}^{2}$ for all the subfaults. The slip distribution and the size clearly indicate that multiple segments of the ERC's long-term forecast ruptured simultaneously.

The synthetic waveforms generally agree with the observed ones at most stations (Fig. 4). The two-stage tsunami observed at offshore gauges (TM-1, TM-2, Iwate M, and Iwate $S$ ) is well reproduced. The initial part of the tsunami, a small negative wave followed by a gradual increase at coastal tide gauge stations (Miyako, Kamaishi, Ofunato and Soma) is also reproduced.

Seafloor deformation calculated from the estimated slip distribution (Fig. 3(b)) shows a very large uplift (>10 m) near the trench axis and about 5-m uplift near the epicenter. Near the coast, subsidence up to $2 \mathrm{~m}$, as observed by the GPS data (GSI, 2011) is predicted. 
Table 1. Slip distributions estimated by tsunami waveform inversion.

\begin{tabular}{|c|c|c|c|c|}
\hline No. & Lat. $\left({ }^{\circ} \mathrm{N}\right)$ & Lon. $\left({ }^{\circ} \mathrm{E}\right)$ & Depth $(\mathrm{km})$ & Slip and error $(\mathrm{m})$ \\
\hline 1 & 39.738 & 144.331 & 0 & $0.00 \pm 0.23$ \\
\hline 2 & 39.3 & 144.20 & 0 & $0.00 \pm 0.15$ \\
\hline 3 & 38.862 & 144.069 & 0 & $5.66 \pm 4.85$ \\
\hline 4 & 38.424 & 143.939 & 0 & $41.15 \pm 17.14$ \\
\hline 5 & 37.986 & 143.810 & 0 & $47.93 \pm 21.49$ \\
\hline 6 & 37.547 & 143.682 & 0 & $8.44 \pm 4.25$ \\
\hline 7 & 37.135 & 143.40 & 0 & $0.00 \pm 1.81$ \\
\hline 8 & 36.730 & 143.07 & 0 & $0.00 \pm 0.87$ \\
\hline 9 & 36.325 & 142.74 & 0 & $1.89 \pm 0.75$ \\
\hline 10 & 35.905 & 142.504 & 0 & $0.63 \pm 0.97$ \\
\hline 11 & 39.836 & 143.778 & 12.1 & $0.00 \pm 0.03$ \\
\hline 12 & 39.398 & 143.651 & 12.1 & $0.81 \pm 0.44$ \\
\hline 13 & 38.960 & 143.523 & 12.1 & $10.67 \pm 6.16$ \\
\hline 14 & 38.522 & 143.397 & 12.1 & $27.84 \pm 11.09$ \\
\hline 15 & 38.084 & 143.271 & 12.1 & $33.79 \pm 18.47$ \\
\hline 16 & 37.646 & 143.146 & 12.1 & $24.11 \pm 9.30$ \\
\hline 17 & 37.233 & 142.867 & 12.1 & $0.00 \pm 2.50$ \\
\hline 18 & 36.828 & 142.540 & 12.1 & $0.00 \pm 0.32$ \\
\hline 19 & 36.423 & 142.213 & 12.1 & $0.00 \pm 0.24$ \\
\hline 20 & 36.003 & 141.979 & 12.1 & $0.00 \pm 0.91$ \\
\hline 21 & 39.934 & 143.224 & 24.2 & $0.00 \pm 0.41$ \\
\hline 22 & 39.496 & 143.100 & 24.2 & $0.00 \pm 0.27$ \\
\hline 23 & 39.058 & 142.977 & 24.2 & $4.86 \pm 3.99$ \\
\hline 24 & 38.620 & 142.853 & 24.2 & $19.56 \pm 9.68$ \\
\hline 25 & 38.182 & 142.731 & 24.2 & $23.38 \pm 12.54$ \\
\hline 26 & 37.744 & 142.609 & 24.2 & $13.13 \pm 5.81$ \\
\hline 27 & 37.331 & 142.333 & 24.2 & $11.13 \pm 5.44$ \\
\hline 28 & 36.926 & 142.009 & 24.2 & $2.23 \pm 1.66$ \\
\hline 29 & 36.521 & 141.684 & 24.2 & $2.25 \pm 2.02$ \\
\hline 30 & 36.101 & 141.454 & 24.2 & $0.54 \pm 0.31$ \\
\hline 31 & 40.032 & 142.670 & 36.3 & $0.00 \pm 0.42$ \\
\hline 32 & 39.594 & 142.549 & 36.3 & $0.00 \pm 0.17$ \\
\hline 33 & 39.156 & 142.430 & 36.3 & $0.00 \pm 0.55$ \\
\hline 34 & 38.718 & 142.309 & 36.3 & $14.64 \pm 8.98$ \\
\hline 35 & 38.280 & 142.190 & 36.3 & $9.46 \pm 4.44$ \\
\hline 36 & 37.842 & 142.071 & 36.3 & $0.00 \pm 0.00$ \\
\hline 37 & 37.429 & 141.798 & 36.3 & $0.00 \pm 1.88$ \\
\hline 38 & 37.024 & 141.477 & 36.3 & $0.00 \pm 0.07$ \\
\hline 39 & 36.619 & 141.155 & 36.3 & $0.00 \pm 0.00$ \\
\hline 40 & 36.199 & 140.928 & 36.3 & $0.00 \pm 1.22$ \\
\hline
\end{tabular}

Location (latitude [Lat.] and longitude [Lon.]) indicates the northeast corner of each subfault.

\section{Discussions and Conclusions}

The large slip estimated near the trench axis is similar to the 1896 Sanriku earthquake (Tanioka and Satake, 1996b), although the 2011 slip was much larger. Large offshore slip is responsible for the very large and destructive tsunami on the Sanriku coast. To confirm this, we computed tsunami waveforms from the large slip near the trench axis, and compared it with the tsunami waveforms at selected offshore stations (Fig. 2). The computed tsunami waveforms show later arrivals than the observed initial tsunami arrivals, but reproduce the large impulsive tsunamis.

Unlike the 1896 earthquake, large slip was also estimated on the plate interface at a deeper depth in the southern Sanriku-oki and Miyagi-oki regions. The initial gradual rise of sea level observed at some stations is due to inter- plate slip (Fig. 2). Large tsunami inundation ( $>5 \mathrm{~km}$ ) in the Sendai plain may be due to such a nearshore, deeper slip on the plate interface. For the 869 Jogan tsunami, a similar large inundation (a few $\mathrm{km}$ ) estimated from the tsunami deposits was reproduced only by an interplate model. A narrow fault near the trench axis ("tsunami earthquake" model) or an outer-rise normal fault model could not produce a large inundation, because of the shorter wavelength of seafloor deformation (Satake et al., 2008).

The inversion of available tsunami waveforms showed that the large tsunami from the 2011 off the Pacific coast of Tohoku Earthquake was produced by both a very large displacement near the trench axis and a deeper interplate slip in the southern Sanriku-oki, Miyagi-oki, and Fukushimaoki regions. The former explains the largest and impul- 

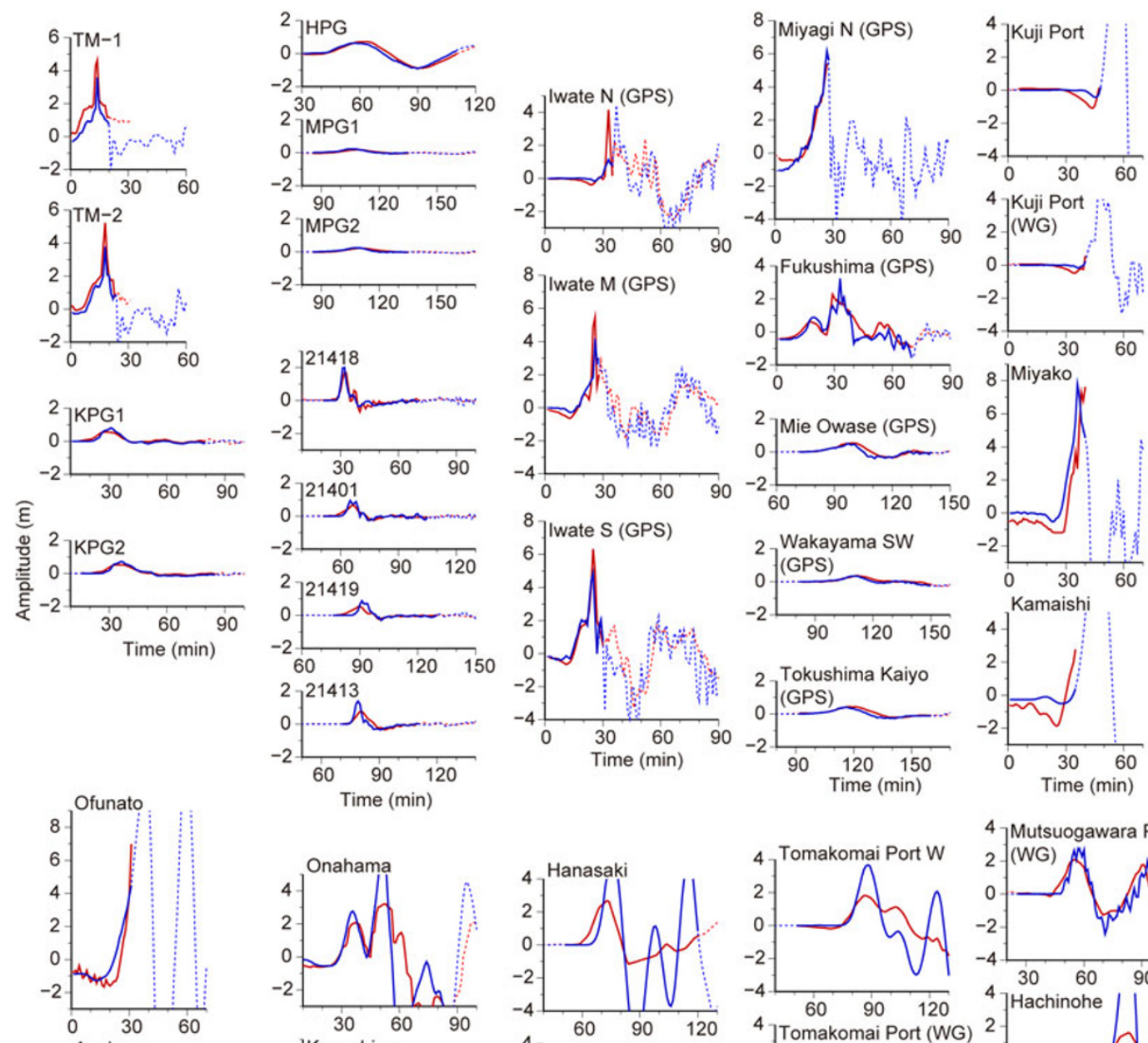

2 Wakayama SW
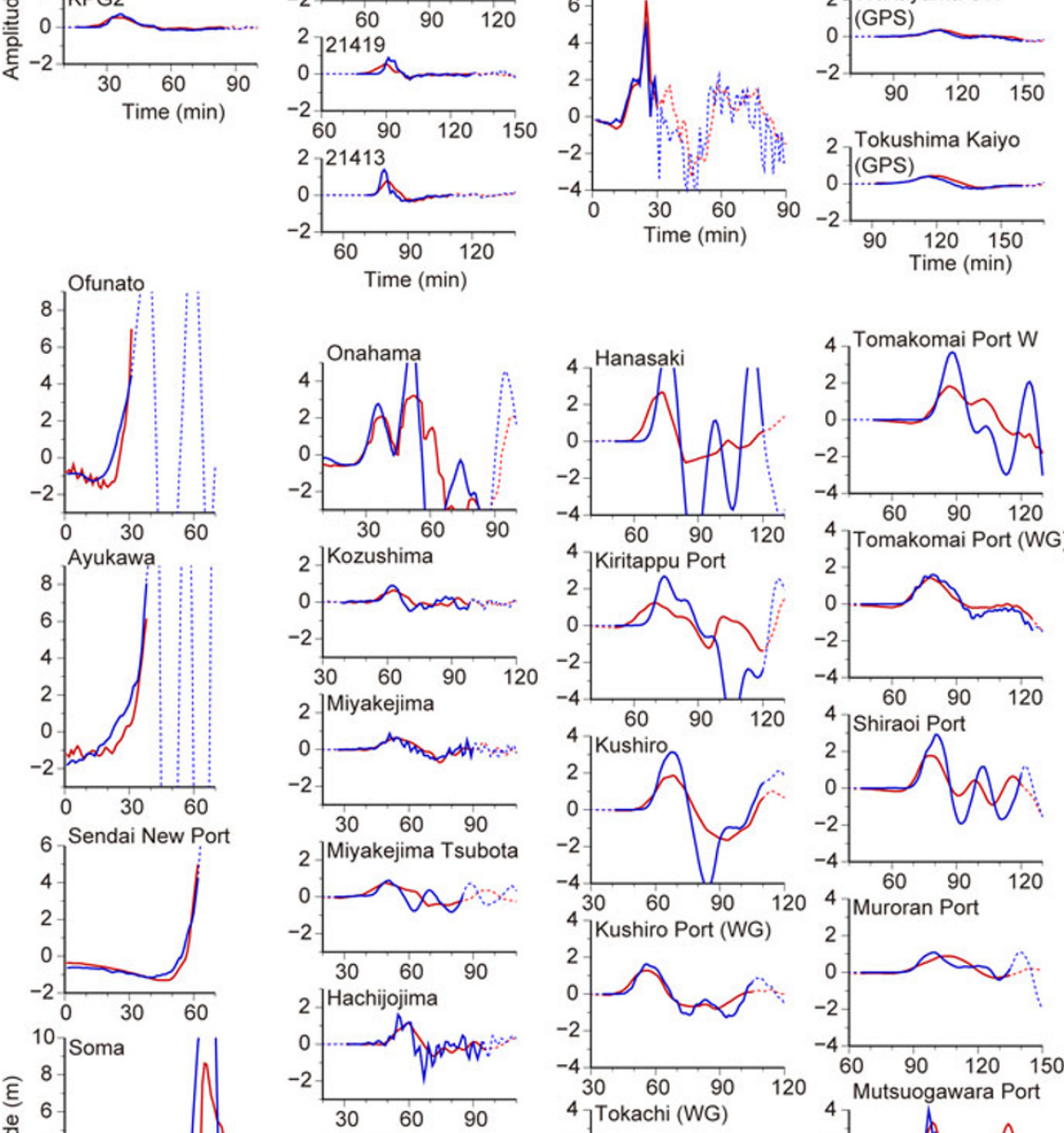

4 Mutsuogawara Port
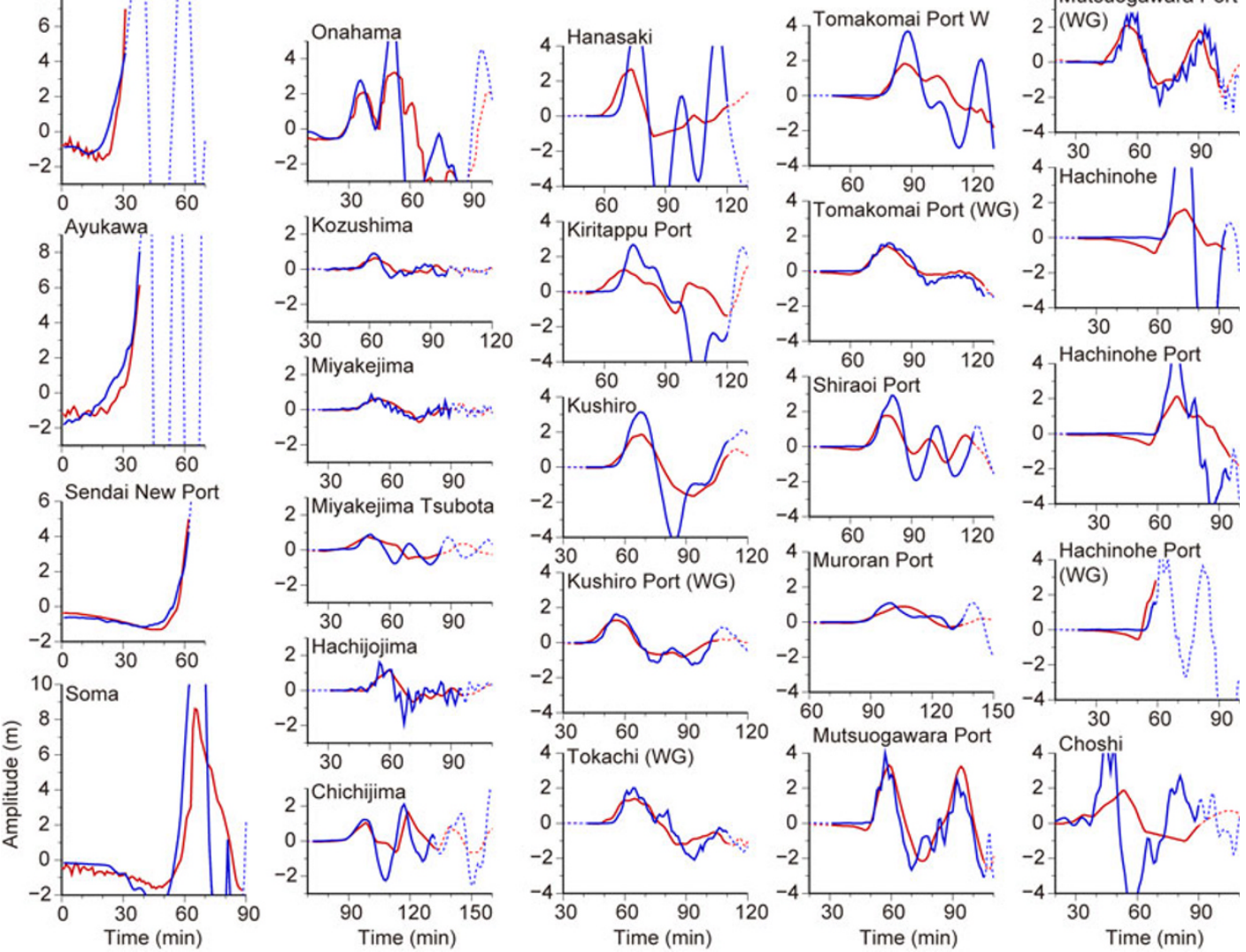

Fig. 4. Comparisons of the observed (red curves) and synthetic (blue curves) tsunami waveforms computed from the estimated slip distribution. Time ranges shown by solid curves are used for the inversions; the dashed parts are not used for the inversions, but shown for comparison. Note the same vertical scales for bottom-pressure gauges (the upper left two columns), GPS wave gauges (upper central two columns) and coastal tide and wave gauges (upper right one column and bottom columns). See Figs. 1 and 3(a) for the station locations.

sive tsunami waveforms, while the latter reproduces the initial part of the tsunami waveforms, as well as the large inundation on the Sendai plain. The survey results of coastal tsunami run-up, for example $>30$ m near the cen- tral Sanriku-oki region, may require additional tsunami source(s), not revealed by available tsunami waveform data. 
Acknowledgments. JCG and JMA provided tide gauge data. Ports and Harbors Bureau (PHB) under the Ministry of Land, Infrastructure, Transport and Tourism (MLIT) and Port and Airport Research Institute (PARI) provided tide gauge, wave gauge and GPS wave gauge data. The data of ocean-bottom tsunami sensors of JAMSTEC and DART of NOAA were downloaded from their web sites. Most of the figures were generated using Generic Mapping Tools (Wessel and Smith, 1998). This research was partially supported by Grants-in-Aid for Scientific Research (B) (No. 21310113), Ministry of Education, Culture, Sports, Science and Technology (MEXT).

\section{References}

Earthquake Research Committee, Long-term forecast of earthquakes from Sanriku-oki to Boso-oki (revised), Headquarters for Earthquake Research Promotion, 80 pp, 2009 (in Japanese).

Fujii, Y. and K. Satake, Tsunami source of the 2004 Sumatra-Andaman Earthquake inferred from tide gauge and satellite data, Bull. Seismol. Soc. Am., 97, S192-S207, 2007.

Geospatial Information Authority of Japan, The 2011 off the Pacific coast of Tohoku Earthquake: Crustal deformation and fault model (preliminary), http://www.gsi.go.jp/cais/topic110313-index-e.html, 2011.

Kanamori, H., Seismological evidence for a lithospheric normal faultingThe Sanriku earthquake of 1933, Phys. Earth Planet. Inter., 4, 289-300, 1971.

Kanamori, H., Mechanism of tsunami earthquake, Phys. Earth Planet. Inter., 6, 346-359, 1972.
Lawson, C. L. and R. J. Hanson, Solving Least Squares Problems, 340 pp., Prentice-Hall, Inc., Englewood Cliffs, N.J., 1974.

Minoura, K. and S. Nakaya, Traces of tsunami preserved in inter-tidal lacustrine and marsh deposits: some examples from northeast Japan, $J$. Geol., 99, 265-287, 1991.

Okada, Y., Surface deformation due to shear and tensile faults in a halfspace, Bull. Seismol. Soc. Am., 75, 1135-1154, 1985.

Satake, K., Y. Namegaya, and S. Yamaki, Numerical simulation of the AD 869 Jogan tsunami in Ishinomaki and Sendai plains, Ann. Rep. Active Fault Paleoearthq. Res., 8, 71-89, 2008 (in Japanese with English abstract).

Tanioka, Y. and K. Satake, Tsunami generation by horizontal displacement of ocean bottom, Geophys. Res. Lett., 23, 861-864, 1996a.

Tanioka, Y. and K. Satake, Fault parameters of the 1896 Sanriku tsunami earthquake estimated from numerical modeling, Geophys. Res. Lett., 23, 1549-1552, 1996b.

The 2011 Tohoku Earthquake Tsunami Joint Survey Group, The 2011 off the Pacific coast of Tohoku Earthquake Tsunami Information, http://www.coastal.jp/tsunami2011/, 2011.

Tichelaar, B. W. and L. J. Ruff, How good are our best models? Jackknifing, bootstrapping, and earthquake depth, Eos Trans. AGU, 70, 593, 605-606, 1989.

Wessel, P. and W. H. F. Smith, New, improved version of the Generic Mapping Tools released, Eos Trans. AGU, 79, 579, 1998.

Y. Fujii (e-mail: fujii@kenken.go.jp), K. Satake, S. Sakai, M. Shinohara, and T. Kanazawa 